\title{
Substituição de agregados minerais por resíduos de concreto na fabricação de pavimento asfáltico
}

\author{
The substitution of mineral aggregates by concrete \\ residues in asphalt pavement manufacturing \\ Gabriela Di Mateos Garcia ${ }^{a}$ \\ Marliton Rocha Barreto ${ }^{b}$ \\ Flávio Alessandro Crispim
}

aMestre em Ciências Ambientais, Universidade Federal de Mato Grosso,

Sinop, MT, Brasil.

End. Eletrônico: gabriela_dimateos@hotmail.com

${ }^{b}$ Professor Associado da Universidade Federal de Mato Grosso, Sinop, MT, Brasil.

End.Eletrônico:mrb.ufmt@gmail.com

'Professor Adjunto da Universidade do Estado de Mato Grosso, Sinop, MT, Brasil. End. Eletrônico: flavio.crispim@unemat.br

doi:10.18472/SustDeb.v9n3.2018.18541

\section{RESUMO}

Pesquisas de materiais que estejam alinhados com os princípios da sustentabilidade têm gerado grande interesse devido ao apelo ambiental. Entre esses materiais destacam-se compósitos produzidos a partir de resíduos de construção civil (RCC), em que o resíduo de concreto contribui significativamente. Este artigo apresenta a análise da viabilidade técnica do emprego de resíduos de blocos de concreto em substituição aos agregados minerais em pavimentação asfáltica do tipo concreto betuminoso usinado a quente (CBUQ). Foram realizados ensaios de caracterização física e mecânica de acordo com as normas técnicas vigentes. Os resultados demonstraram que os compósitos com substituições de agregados minerais, de até $40 \%$ em massa, atendem aos requisitos estabelecidos e podem ser utilizados na pavimentação asfáltica.

Palavras-chave: Sustentabilidade; Resíduos sólidos; Agregados; Mistura asfáltica. 


\begin{abstract}
$x$ Material research that is combined with sustainability principles has generated great interest due to the environmental appeal. Composites produced from civil construction waste (CCW) stand out among those materials and concrete residue represents a significant part of $i t$. This paper presents the feasibility analysis of the use of concrete block waste replacing mineral aggregates in asphalt paving of Hot Mix Asphalt Concret (HMAC). Physical and mechanical characterization tests were performed according to the current technical standards. The results showed that composites with up to $40 \%$ of mineral aggregate replacement by mass, satisfy the established requirements and may be used in asphalt paving.
\end{abstract}

Keywords: Sustainability; Solid waste; Aggregates; Asphalt mix.

\title{
1 INTRODUÇÃO
}

O mercado da construção civil gera elevada quantidade de resíduos. Visando o desenvolvimento sustentável, o descarte de materiais deve ser minimizado e novos métodos devem ser adotados para que, além do reaproveitamento, novas gerações desfrutem dos recursos naturais ainda existentes.

Os resíduos da construção civil (RCC) são todos os materiais que não podem ser aproveitados na atividade de construir e são descartados, podendo ser gerados pela atividade ou na indústria de fabricação dos insumos de construção (SILVA; FERNANDES, 2012).

Persich e Silveira (2011) relataram que a reciclagem de entulhos ainda não é uma técnica disseminada e muitas vezes os resíduos são encaminhados para terrenos baldios. Silva e Fernandes (2012) expuseram que entre os resíduos depositados nesses terrenos encontra-se elevada quantidade de fragmentos de concreto, como, por exemplo, artefatos de concreto que não podem ser utilizados devido à presença de imperfeições, trincas e rachaduras.

Pesquisas exploratórias, como a de Reyes-Ortiz, Álvarez e Valdés-Vidal (2014), Rodrigues e Fucale (2014) e Souza, Assis e Souto (2014), apontaram que é possível reaproveitar blocos de concreto e outros produtos rejeitados como matéria-prima de artefatos para compor outros modelos de misturas. Para que o resíduo reciclado como agregado seja utilizado de forma eficiente, deve-se determinar em qual compósito o material pode ser aplicado sem prejuízo para as características deste.

Segundo Paiva e Cartaxo (2014), um dos tipos de revestimento asfáltico mais empregados no Brasil, o concreto betuminoso usinado a quente (CBUQ), possui composição que se assemelha ao concreto convencional (agregados e aglomerantes), entretanto, a mistura deixa de ter o Cimento Portland como aglomerante para ser composta por cimento asfáltico de petróleo (CAP). Dessa forma, é possível pensar na aplicação do agregado reciclado que já foi empregado na composição de concreto de cimento, com sucesso, para a composição do concreto asfáltico.

A justificativa deste estudo centra-se na substituição de agregados minerais por agregados provenientes de resíduos e é uma alternativa viável pois, além da minimização do impacto ambiental causado pela mineração ou eliminação do entulho em locais inadequados, este é dirigido a um destino útil e sustentável.

Nesse sentido, o objetivo do estudo foi analisar o processo de fabricação do CBUQ, identificando seus componentes minerais e aplicando o conceito de sustentabilidade ao incorporar o máximo possível de resíduos de concreto em substituição a esses materiais.

\section{DESENVOLVIMENTO SUSTENTÁVEL E CONSTRUÇÃO CIVIL}

Do ponto de vista empresarial, o desenvolvimento sustentável só é possível quando novas soluções tecnológicas são adotadas como estratégias de negócio atendendo às necessidades da organização, do ser humano e da comunidade, ao mesmo tempo que preserva os recursos naturais (PEREIRA, 2010). 
Segundo Pereira (2010), as obras civis geram grande impacto ao meio ambiente, começando pela extração de recursos naturais para fabricação de seus materiais até a geração de resíduos durante sua atividade. A preocupação com relação a esse segmento tem aumentado e o reaproveitamento de materiais tem sido boa alternativa para aumentar a sustentabilidade.

\subsection{RESÍDUOS DE CONSTRUÇÃO CIVIL (RCC)}

Os resíduos de construção são classificados pela Resolução no 307 do Conselho Nacional do Meio Ambiente de 2002 (CONAMA, 2002) como os provenientes de construções, reformas, reparos e demolições de obras de construção civil, que podem ser divididos em quatro classes: (A) recicláveis como os agregados - objeto de estudo deste trabalho; (B) recicláveis para outras destinações, como plásticos, papel/papelão, metais e gesso; (C) sem tecnologia disponível para reciclagem e aproveitamento e (D) perigosos, como tintas, solventes, óleos, fibrocimentos com amianto, entre outros.

No Brasil, 53\% dos resíduos sólidos são compostos por resíduos de construção (LIMA; CABRAL, 2004). Dias e Júnior (2016) citam que a disposição em locais inapropriados e os aterros clandestinos existentes, devido à falta de gerenciamento, tornaram-se uma realidade no País. Em 2002, com a aprovação da Resolução no 307 do Conama, critérios e procedimentos para a gestão de RCC ficaram estabelecidos no Brasil (CONAMA, 2002).

\section{INCORPORAÇÃO DE RESÍDUOS NA INFRAESTRUTURA URBANA}

Em 2012, o Instituto de Pesquisa Econômica Aplicada (Ipea) publicou o diagnóstico dos resíduos da construção civil, visando subsidiar as discussões sobre a elaboração do Plano Nacional de Resíduos Sólidos. Foi exposto que a composição média dos resíduos provenientes de obras no Brasil está subdividida primeiramente por argamassa (63\%), seguida por concreto em blocos (29\%), objeto de estudo, outros - como madeira, metais e cerâmica (7\%) e orgânicos (1\%).

A indústria da construção civil precisa, além de minimizar a geração de resíduos, criar métodos em que eles possam ser reaproveitados (BAPTISTA; VIEIRA; ROMANEL, 2013). Empregá-los na pavimentação asfáltica é uma alternativa que oferece opção de reciclagem do resíduo com efetividade, tendo em vista que o volume de materiais utilizados para a pavimentação asfáltica é elevado (PINTO, 2006) com relação a outras finalidades.

A superfície do pavimento asfáltico é formada por agregado mineral, concreto asfáltico (subproduto do petróleo), combinação de rochas e areia. Além da escassez de matéria-prima, há necessidade de reduzir custo. Por esse motivo, torna-se imprescindível a utilização de técnicas de recuperação como a reciclagem (SANTOS; DEMUELENAERE, 2018).

\subsection{CONCRETO ASFÁLTICO (CA), CONCRETO BETUMINOSO USINADO A QUENTE (CBUQ) E PAVIMENTOS SUSTENTÁVEIS}

Bernucci et al. (2010) descreveram que a mistura proporcionada de agregados de vários tamanhos e material betuminoso, denominado concreto asfáltico (CA), é um dos tipos de pavimento mais empregado no Brasil e, quando o concreto asfáltico é aquecido em temperaturas previamente escolhidas, em função da característica viscosidade-temperatura do ligante (betume ou asfalto), o CA recebe a denominação de concreto betuminoso usinado a quente (CBUQ).

De acordo com a Norma do Departamento Nacional de Infraestrutura de Transportes (Dnit) 031/2006 ES, os materiais constituintes do concreto asfáltico são: agregado graúdo, agregado miúdo, material de enchimento (fíler) e ligante asfáltico, devendo todos satisfazer às normas pertinentes e às especificações aprovadas pelo órgão. A mesma norma estabelece os ensaios e critérios para a execução dos serviços (DNIT, 2006). 
Tomando como base a composição analítica para CBUQ demonstrada pelo Sistema Nacional de Pesquisa de Custos e Índices da Construção Civil (Sinapi), código PAVI 72962, para cada metro quadrado de pavimento, com espessura de 3 centímetros, por exemplo, utilizam-se em média $64 \mathrm{~kg}$ de agregados (CAIXA, 2017). Isso significa que, para a fabricação de um dos principais revestimentos de vias utilizados no País (PAIVA; CARTAXO, 2014), a quantidade de agregados envolvidos em cada metro quadrado de rodovia é significativa.

Foi evidenciado diversas vezes que a viabilidade econômica não precisa ser sacrificada para alcançar a sustentabilidade e a equidade social. Práticas de engenharia responsáveis, guiadas pela ética ambiental da comunidade, podem resultar na redução dos custos do ciclo de vida e suavizar impactos ambientais e econômicos que se projetam para o futuro.

\section{Agregados}

O agregado graúdo pode ser pedra britada, escória, seixo rolado ou outro material indicado em especificações complementares e deve apresentar desgaste "Los Angeles" igual ou inferior a 50\% pelo método de ensaio do Departamento Nacional de Estradas de Rodagem (DNER) ME 035 - Agregados. Determinação da abrasão "Los Angeles" (DNER, 1998). Os agregados graúdos são os grãos que passam pela peneira com abertura de $75 \mathrm{~mm}$ e ficam retidos na peneira com abertura de malha de $4,75 \mathrm{~mm}$ (ABNT, 2005).

Os agregados classificados como miúdos são os grãos que passam pela peneira com abertura de 4,75 mm, mas ficam retidos na abertura de $150 \mu \mathrm{m}$, como areia, pó de pedra, mistura de ambos ou outro material indicado nas especificações complementares. Suas partículas individuais devem ser resistentes, estando livres de torrões de argila e de substâncias nocivas (ABNT, 2005), além de apresentar equivalente de areia igual ou superior a 55\% no ensaio DNER-ME 054/97 - Equivalente de areia (DNER, 1997).

O material de enchimento (fíler) deve estar seco e isento de grumos, também ser constituído por materiais minerais finamente divididos, tais como cimento Portland, cal extinta, pós-calcários, cinza volante, entre outros, de acordo com a Norma DNER-EM 367 - Material de enchimento para misturas betuminosas (DNER, 1997).

\section{Betume}

Betume é uma mistura líquida de alta viscosidade, coloração escura e inflamável. É formado por compostos químicos (hidrocarbonetos), e pode ocorrer tanto na natureza como ser obtido artificialmente, em processo de destilação do petróleo (COBBOLD et al. 2014). O cimento asfáltico (CA) ou cimento asfáltico de petróleo (CAP) é um betume obtido pelo processo de destilação do petróleo pelas refinarias (ABEDA, 2010).

As discussões acerca da implantação de pavimentos sustentáveis não são recentes. Em 1992 pesquisadores americanos já citavam misturas, como asfalto-borracha, ecopavimento, asfalto permeável, entre outras tecnologias, que garantem soluções ambientais.

Estudos realizados em vias de baixo tráfego em São Paulo expõem que o uso do agregado reciclado em pavimentação deve ser incentivado, pois seu preço é inferior ao de materiais convencionais e a destinação adequada para o grande volume de resíduo de construção e demolição gerado tende a reduzir problemas ambientais presentes e futuros (ABDOU; BERNUCCI, 2007).

\section{MATERIAL E MÉTODOS}

A pesquisa de que trata este artigo foi conduzida em dois locais: na Universidade do Estado de Mato Grosso (Unemat) - Campus Sinop e no laboratório de uma das empresas que prestam serviços de pavimentação asfáltica na região norte de Mato Grosso. As atividades realizadas foram divididas em quatro etapas: definição dos resíduos utilizados na pesquisa, caracterização dos agregados, 
determinação dos parâmetros físicos e análise de viabilidade técnica (Figura 1).

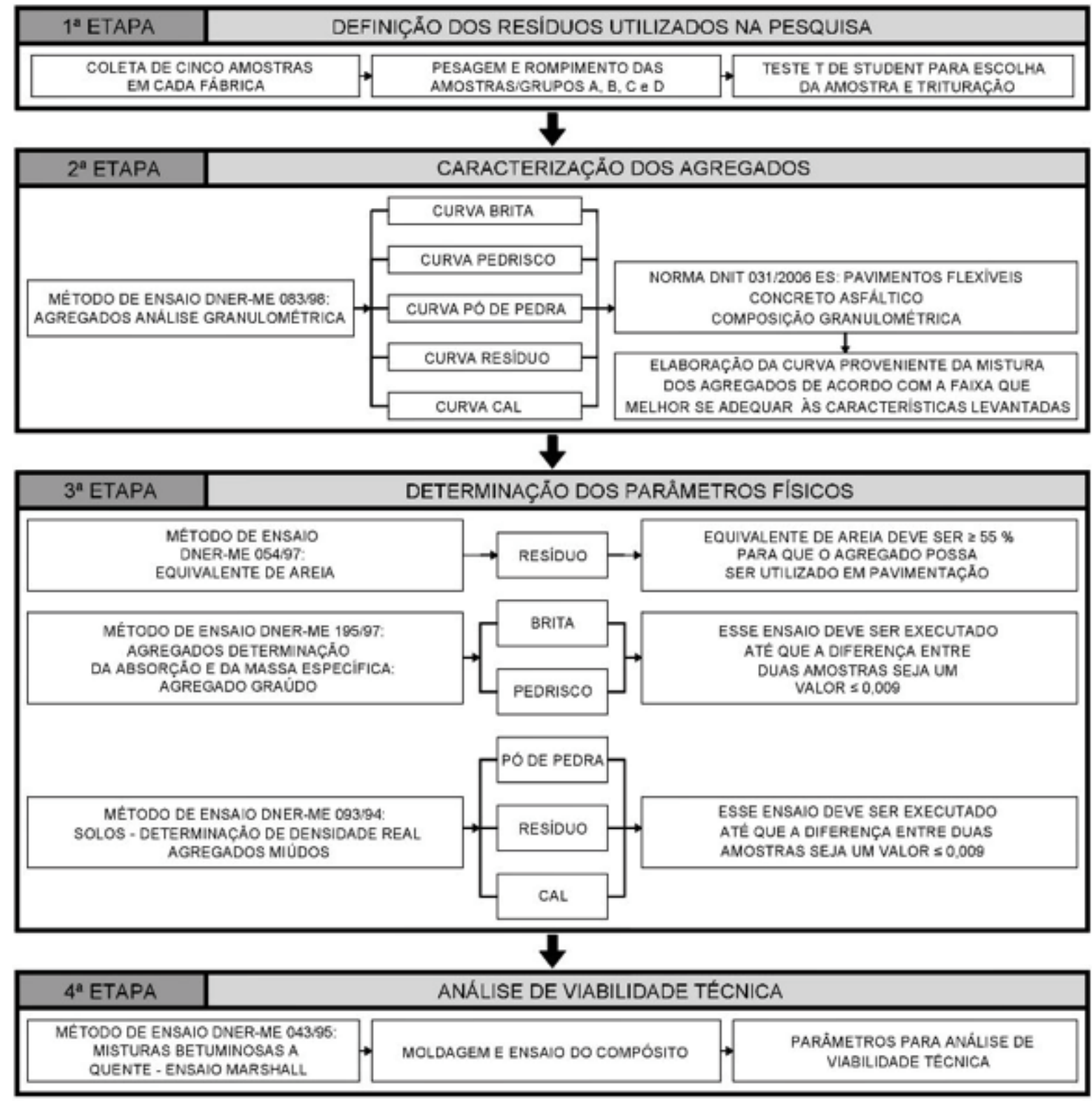

Figura 1 - Ordem das atividades realizadas

Fonte: GARCIA, 2018.

Os experimentos foram executados no período de janeiro a setembro de 2017. Os ensaios foram executados seguindo as etapas principais e secundárias, explanadas detalhadamente nos tópicos a seguir. Todos os ensaios foram realizados de acordo com as normas técnicas vigentes no País (GARCIA, 2018).

\subsection{DEFINIÇÃO DOS RESÍDUOS UTILIZADOS NA PESQUISA}

Na primeira etapa realizou-se a coleta de cinco amostras de blocos de concreto em cada uma das quatro fábricas da cidade, denominadas A, B, C e D. Os grupos de amostras passaram por pesagem e rompimento para definir, por meio do teste T de "Student" para amostras independentes, qual amostra representava a fabricante que obtinha características físicas que representasse a média entre elas. No fabricante escolhido foi coletado o resíduo que seria utilizado para as análises, que foi fragmentado em 
equipamento triturador.

\subsection{CARACTERIZAÇÃO DOS AGREGADOS UTILIZADOS}

Os agregados utilizados foram: naturais, compostos por calcário em diferentes granulometrias (brita, pedrisco, pó de pedra e cal) e reciclados compostos de resíduos de blocos de concreto provenientes de fabricantes locais de Sinop-MT, que substituíram parcialmente os naturais.

Na segunda etapa, todos os agregados passaram pelo ensaio de análise granulométrica, método 083, definido pelo DNER (1998). Para compor a mistura do concreto asfáltico, existem algumas condições granulométricas específicas, o Dnit estabelece três faixas: A, B e C, que variam de acordo com a granulometria da mistura dos agregados, evidenciada por meio da especificação de serviço 031, que estabelece as condições granulométricas específicas para a composição da mistura do concreto asfáltico (DNIT, 2006).

Por meio do ensaio de granulometria do resíduo, foi analisado que os grãos começaram a ficar retidos a partir da peneira № 04 com abertura de 4,8 mm, similar ao pó de pedra. Dessa forma, a faixa adotada foi a C, tendo em vista que, além de ser uma das mais empregadas para as obras de pavimentação, A e $B$ demandariam utilização de agregado graúdo (grãos que ficam retidos nas peneiras de maior abertura como 2", $1 \frac{1}{2}$ " e 1") e, por meio das análises de peneiramento, foi verificado que não há agregados graúdos na composição do resíduo.

De acordo com o Dnit (2006), a composição do concreto asfáltico exige agregados de diferentes granulometrias. Dessa forma, deve ser feita a composição englobando diferentes porcentagens de cada tamanho, ou seja, a mistura entre eles deve gerar uma curva que esteja dentro dos limites de tolerância estabelecidos.

Para determinar qual a porcentagem máxima de agregados de origem natural que poderiam ser substituídos por resíduo, diferentes porcentagens para cada agregado foram testadas em planilha eletrônica até que a curva se enquadrasse nos limites de tolerância da faixa C especificada pelo Dnit.

O Dnit (2006) estabelece, por meio da especificação de serviço e considerando o coeficiente de segurança (CS2), o teor de betume para cada faixa granulométrica. Esse teor é a porcentagem de CAP que será incorporada à mistura dos agregados para que seja moldado o corpo de prova; na faixa C esse teor deve estar dentro do intervalo entre $4,5 \%$ e $9,0 \%$.

\subsection{DETERMINAÇÃO DOS PARÂMETROS FÍSICOS PARA OS AGREGADOS}

$\mathrm{Na}$ terceira etapa foram realizados ensaios para determinação de outros parâmetros físicos dos materiais, fundamentais para que o ensaio de pavimento fosse realizado.

Desse modo, o primeiro ensaio foi o DNER-ME 054/97: equivalente de areia, que define a porcentagem de areia que compõe o material analisado. Para ser utilizado na pavimentação asfáltica, o material deve apresentar sua porcentagem de areia igual ou superior a 55\%. Esse ensaio foi executado com o pedrisco, o resíduo e o pó de pedra.

O segundo ensaio, DNER-ME 195/97, referente à determinação da absorção e da massa específica de agregado graúdo, e o terceiro, DNER-093/94 - determinação de densidade real, estabeleceram a absorção e densidade para todos os agregados em análise.

O material de enchimento (fíler) utilizado foi a cal hidratada $\mathrm{CH}$-III. De acordo com as informações extraídas em suas especificações técnicas, a cal obedece aos critérios da norma DNER-EM 367 Material de enchimento para misturas betuminosas (DNER, 1997). 


\subsection{ANÁLISE DE VIABILIDADE TÉCNICA}

Na quarta, e última etapa, foi realizada a análise de viabilidade técnica pelo Ensaio Marshall (DNER, 1995), que apresenta parâmetros como: teor ótimo de ligante, volume de vazios reais, relação betume/ vazios, estabilidade e fluência, que foram comparados aos estabelecidos pela norma.

Conforme o Dnit (2006), além de respeitar as respectivas tolerâncias no que diz respeito à granulometria, a quantidade de CAP deve estar dentro do intervalo percentual estabelecido para ligante asfáltico pelo projeto da mistura, entre $4,5 \%$ a $9,0 \%(+/-0,3 \%)$ no caso da faixa $\mathrm{C}$ para camada de rolamento. $\mathrm{Na}$ pesquisa, foi utilizado o CAP 50/70 (ANP, 2005). O material foi escolhido em função de seu ponto de amolecimento (menor do que as outras categorias), possuindo maior trabalhabilidade, além disso, é o mais utilizado em orçamentos do setor público (SINFRA, 2017).

Para verificação dos critérios estabelecidos, foi realizada a dosagem de betume segundo o método de ensaio DNER-ME 043/95: Misturas Betuminosas a Quente - Ensaio Marshall. Essa norma apresenta os procedimentos para determinação de estabilidade e fluência de misturas betuminosas de cimento asfáltico, ou seja, os agregados foram colocados na estufa para que estivessem completamente secos para a moldagem, em seguida cada material que compõe a amostra foi pesado de acordo com o cálculo estabelecido. Esses materiais foram homogeneizados em alta temperatura, posteriormente os corpos de prova foram compactados. Foram moldadas três amostras para cada um dos cinco teores de CAP com base no valor médio de $5 \%$, variando 0,5 e 1,0 abaixo e acima desse valor e formando os teores: $4 \%, 4,5 \%, 5 \%, 5,5 \%$ e $6 \%$.

Os percentuais foram considerados tendo em vista que o coeficiente de $6 \%$ é o admitido pela composição publicada pelo Sinapi (CAIXA, 2017), o teor de $5 \%$ é muito utilizado comercialmente e $4 \%$ seria o melhor em quesitos financeiros. As amostras são pesadas, ficam em banho-maria a 60 ㄷ, e, por fim, são rompidas mediante compressão diametral, sendo obtidos os parâmetros físicos e mecânicos.

\section{RESULTADOS E DISCUSSÃO}

Ao realizar a análise da curva granulométrica obtida, foi verificado que a maior parte de sua composição era formada por agregados miúdos. De acordo com a faixa granulométrica estabelecida (Faixa C do Dnit), a composição em que era possível utilizar maior quantidade desses resíduos foi: $22 \%$ de brita, $1,27 \%$ de pedrisco, $40 \%$ de resíduo, $6 \%$ de pó de pedra e $5 \%$ de cal (Tabela 1 ). Com essas quantidades de cada material, a curva se adaptou entre os valores mínimos e máximos estabelecidos (Figura 2).

Tabela 1 - Porcentagem dos agregados que formam a nova composição enquadrados na faixa $C$ do Departamento Nacional de Infraestrutura de Transportes (Dnit). P = Porcentagem passante, $\mathrm{C}=$ Porcentagem calculada. 


\begin{tabular}{cccccccccccccc}
\hline \multirow{2}{*}{ Peneira } & \multicolumn{3}{c}{ Brita 1} & \multicolumn{3}{c}{ Pedrisco } & \multicolumn{2}{c}{ Resíduo } & \multicolumn{2}{c}{ Pó de pedra } & \multicolumn{2}{c}{ Cal } & \multirow{2}{*}{ Resultado } \\
\cline { 2 - 10 } & & $\%$ útil & $22 \%$ & $\%$ útil & $27 \%$ & $\%$ útil & $40 \%$ & $\%$ útil & $6 \%$ & $\%$ útil & $5 \%$ & Total \\
\hline (mm) & pol. & P. & C. & P. & C. & P. & C. & P. & C. & P. & C. & P. \\
25,4 & $1 "$ & 100,00 & 22,00 & 100,00 & 27,00 & 100,00 & 40,00 & 100,00 & 6,00 & 100,00 & 5,00 & 100,0 \\
19,1 & $3 / 4$ & 100,00 & 22,00 & 100,00 & 27,00 & 100,00 & 40,00 & 100,00 & 6,00 & 100,00 & 5,00 & 100,0 \\
12,7 & $1 / 2$ & 60,80 & 13,38 & 100,00 & 27,00 & 100,00 & 40,00 & 100,00 & 6,00 & 100,00 & 5,00 & 91,4 \\
9,5 & $3 / 8$ & 21,08 & 4,64 & 98,88 & 26,70 & 100,00 & 40,00 & 100,00 & 6,00 & 100,00 & 5,00 & 82,3 \\
4,8 & $N^{\circ} 04$ & 2,82 & 0,62 & 35,96 & 9,71 & 92,96 & 37,18 & 99,74 & 5,98 & 100,00 & 5,00 & 58,5 \\
2,0 & $N^{\circ} 10$ & 1,41 & 0,31 & 4,27 & 1,15 & 64,35 & 25,74 & 76,41 & 4,58 & 100,00 & 5,00 & 36,8 \\
0,42 & $N^{\circ} 40$ & 0,79 & 0,17 & 1,83 & 0,49 & 25,09 & 10,03 & 23,49 & 1,41 & 93,28 & 4,66 & 16,8 \\
0,18 & $N^{\circ} 80$ & 0,63 & 0,14 & 1,38 & 0,37 & 4,78 & 1,91 & 13,94 & 0,84 & 76,23 & 3,81 & 7,1 \\
0,075 & $N^{\circ} 200$ & 0,54 & 0,12 & 1,12 & 0,30 & 1,72 & 0,69 & 10,12 & 0,61 & 59,54 & 2,98 & 4,7 \\
\hline
\end{tabular}

Fonte: GARCIA, 2018.

Figura 2 - Limites da faixa C estabelecida pelo Departamento Nacional de Infraestrutura de Transportes (Dnit) e curva granulométrica da mistura avaliada. Obs. Numeração American Society for Testing and Materials (ASTM) das peneiras na curva.

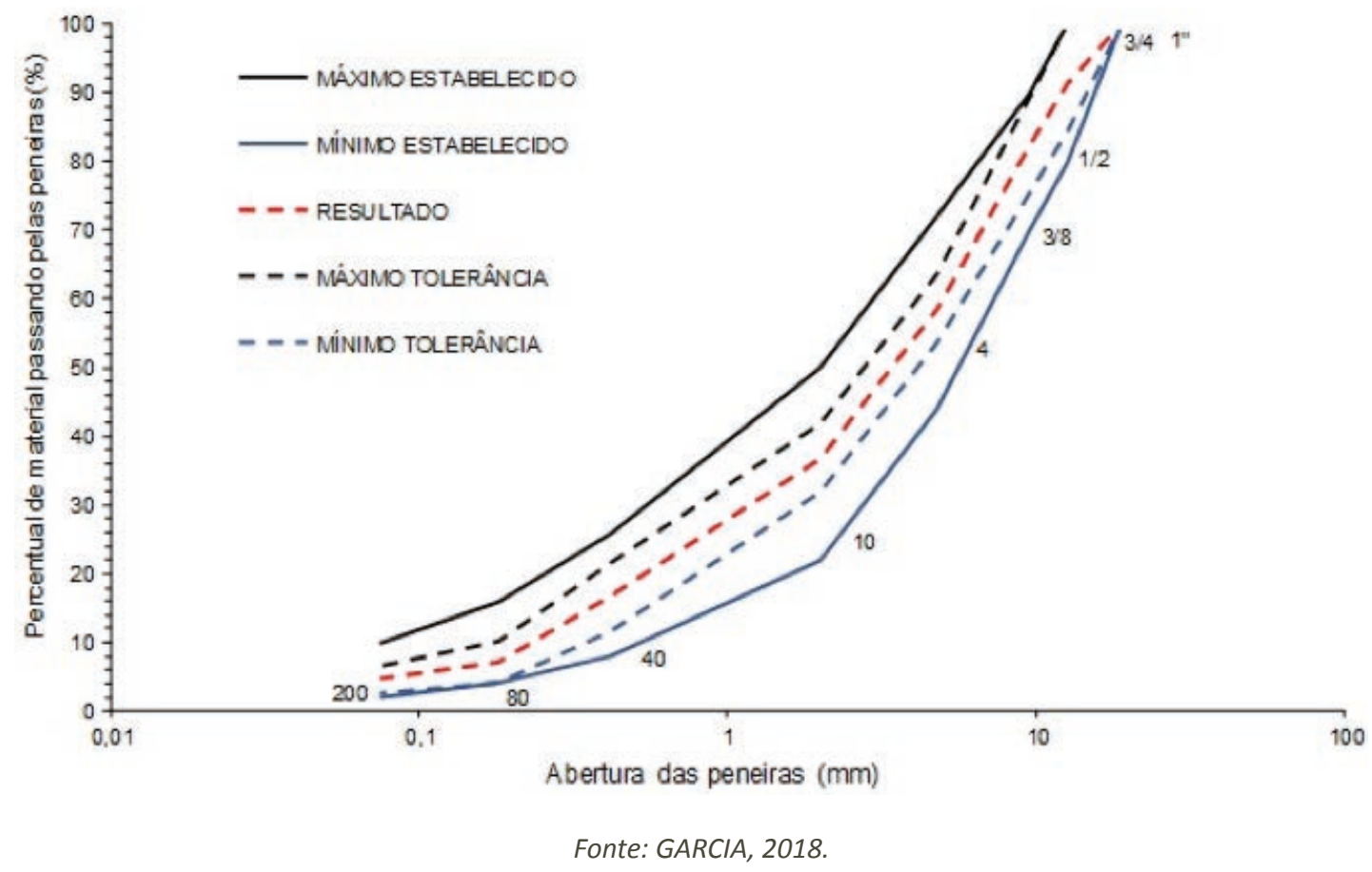

Na Figura 2, as linhas contínuas externas em azul e preto são os limites máximos e mínimos especificados pela faixa C do Dnit, em vermelho tracejada a composição obtida com $40 \%$ de resíduo e em azul e preto tracejadas os mínimos e máximos aceitos com relação à composição granulométrica do novo compósito. Com esse resultado, constatou-se que a relação entre a porcentagem do material da mistura de agregados de origem natural e reciclados passante pelos diferentes tamanhos de peneiras se enquadra nos limites estabelecidos. 
Foram testadas diversas porcentagens em planilha eletrônica, no entanto, $40 \%$ de resíduos foram o máximo em que a curva se enquadrava de maneira satisfatória dentro dos limites estabelecidos. 0 estudo de Passadín e Pérez (2013) incorporou 30\% do mesmo resíduo em CBUQ e essa porcentagem só foi possível mediante análise de comportamento da curva granulométrica dos agregados minerais e reciclados combinados, ou seja, não basta estabelecer uma quantidade de resíduo para a mistura. Independentemente de sua origem, é preciso analisar como vai se ajustar granulometricamente o resíduo em conjunto com as outras parcelas de agregados.

Somente analisando a composição e comparando com os limites estabelecidos na norma do DNER por meio da curva granulométrica, pode se estabelecer que uma determinada composição está apta para integrar a mistura de CBUQ.

Com relação ao ensaio equivalente de areia, a média dos resultados obtidos para o resíduo foi de $88 \%$, enquadrando-se no valor de $55 \%$ ou mais estabelecido pela norma DNIT 031/2006, podendo ser aplicado no pavimento asfáltico. Esse valor é semelhante quando comparado com a pesquisa de Pestana (2008) onde foram incorporados resíduos de matrizes cimentícias na mistura de CBUQ e o resultado obtido para o equivalente de areia foi $83 \%$, próximo ao obtido nesta pesquisa.

A caracterização das misturas asfálticas com bom desempenho demanda balanço entre praticidade e rigor, portanto, é dada preferência aos aspectos considerados de maior relevância para previsão do desempenho das misturas asfálticas em campo, como estabilidade e fluência.

Para determinar o teor ótimo de CAP 50/70 a ser aplicado na mistura, elaborou-se um gráfico com o cruzamento de três resultados obtidos: no eixo horizontal os teores de betume testados, na vertical acima do eixo horizontal o Volume de Vazios (V.V) e na vertical abaixo do eixo horizontal a Relação Betume/Vazios (R.B.V). Interligando os dados chegou-se ao intervalo ideal (entre 5,15\% e 5,50\%) e ao teor ótimo de 5,15\% (Figura 3).

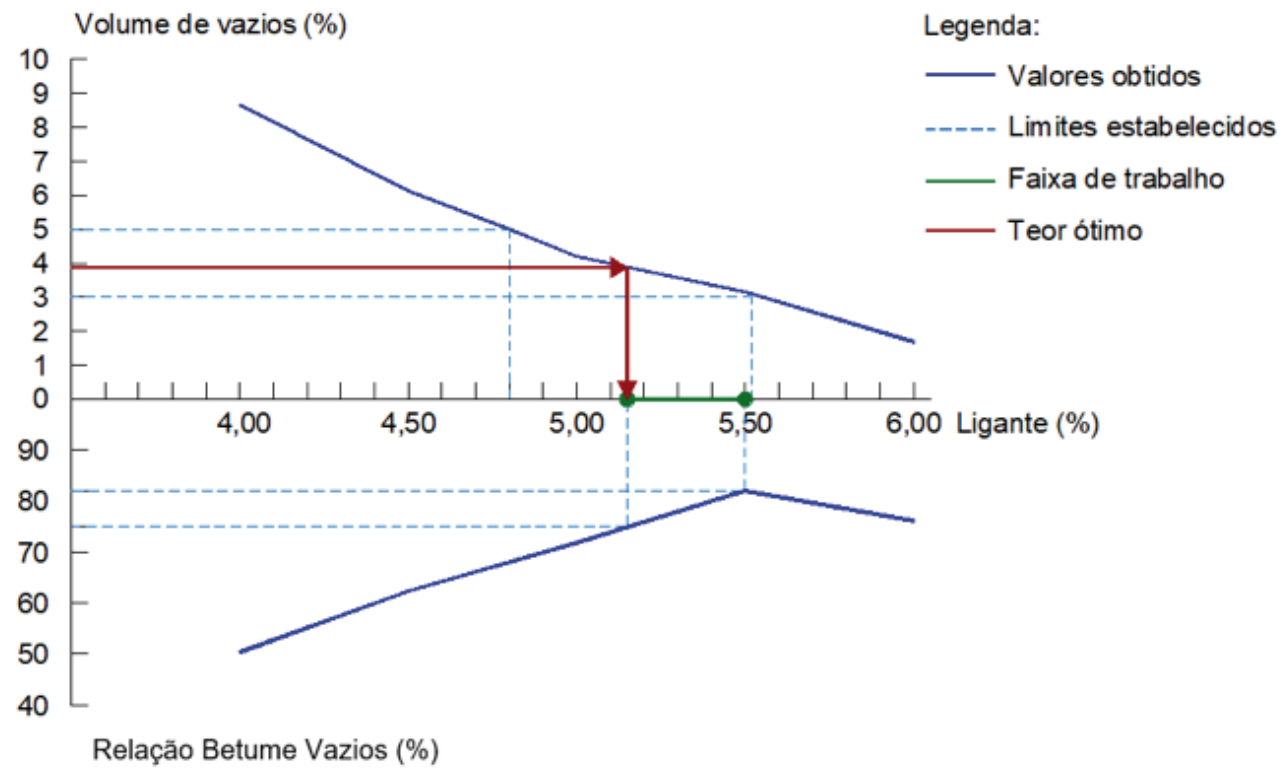

Figura 3 - Determinação do teor ótimo de betume do novo compósito Fonte: GARCIA, 2018.

Segundo a especificação de serviço Dnit 031/2016 ES para a faixa C, o intervalo com relação ao teor ótimo é de $4,50 \%$ a $9,00 \%$, o resultado obtido foi $5,15 \%$. Além de satisfazer as normas do Dnit, está dentro da faixa de trabalho (Figura 3), entre 5,15\% a 5,50\%. A porcentagem de 5,15 foi admitida devido 
à relação betume/vazios, pela questão econômica de que o material mais oneroso do CBUQ é o CAP.

Brasileiro et al. (2014) testaram uma mistura com 50\% de resíduos de construção civil (contendo concreto, cerâmica, mármore e outros) em CBUQ, uma elevada quantidade de resíduos que se enquadrou em todos os parâmetros do Dnit. Porém, essa quantidade consumiu 6,71\% de ligante, resultando em um custo elevado. $O$ ideal é projetar um traço em que se utilize grande quantidade de agregados de concreto, com um menor consumo possível de ligante, de forma a garantir sua viabilidade econômica.

O percentual de resíduo englobado no objeto de pesquisa é menor do que os obtidos por Wesseling (2005) para uma mistura de CBUQ utilizando resíduos de agregado siderúrgico (escória de aciaria) em $85 \%$ e resíduo de areia de fundição em $15 \%$. Percebe-se que há um equilíbrio entre incorporação de agregados reciclados e desempenho técnico. Segundo esse autor, o máximo de teor ótimo foi de 7,0\%, algo que está dentro dos limites estabelecidos pelas normas do Dnit, porém, distante do ideal com relação a custo.

A porcentagem de volume de vazios seguindo o teor ótimo admitido é de $4,05 \%$, sendo que a norma admite um valor dentro do intervalo de $3 \%$ a $5 \%$. A Relação Betume/Vazios (RBV) alcançada foi de $75 \%$, quando a norma exige um valor entre $75 \%$ a $82 \%$. Comparando com os resultados obtidos por Bonet (2003) para uma mistura de CBUQ utilizando resíduos de areia de fundição (RAF) em 8\%, o RBV foi de $75,4 \%$ e o volume de vazios $4 \%$, ou seja, similares aos obtidos na pesquisa e dentro dos limites estabelecidos pelas normas do Dnit.

Foi medida a estabilidade da mistura por meio de um ensaio de compressão diametral e com o teor ótimo de betume chegou-se a $1.250 \mathrm{~kg}$, quando a norma especifica no mínimo $500 \mathrm{~kg}$. A fluência foi medida em ensaio de compressão diametral, sendo que foi medido o valor de $3,4 \mathrm{~mm}$ para a mistura testada, satisfazendo a norma que estabelece um valor entre $2,0 \mathrm{~mm}$ a $4,5 \mathrm{~mm}$.

Assim, o revestimento CBUQ com teor de betume 5,15\% (CAP 50/70), composto por $40 \%$ de resíduos de blocos de concreto, $22 \%$ de brita, $1,27 \%$ de pedrisco, $6 \%$ de pó de pedra e $5 \%$ de cal atende aos requisitos estabelecidos pelo Dnit (2006) e aos ensaios pertinentes, sendo viável tecnicamente. Todos os resultados da análise de viabilidade técnica obtidos foram resumidos na Tabela 2.

Tabela 2 - Análise comparativa dos resultados determinantes para a análise de viabilidade técnica

\begin{tabular}{lcc}
\hline Característica & Resultados & Especificação Dnit/DNER \\
\hline Teor ótimo de ligante (\%) & 5,15 & $4,5-9,0$ \\
Densidade aparente $\left(\mathrm{g} / \mathrm{cm}^{3}\right)$ & 2,30 & não há especificação \\
Vazios Reais (\%) & 4,05 & $3-5$ \\
Relação Betume/Vazios (R.B.V) (\%) & 75,00 & $75-82$ \\
Estabilidade (Kg) & $1.250,00$ & mínimo 500 \\
Fluência (mm) & 3,40 & $2,0-4,5$ \\
& & \\
\hline
\end{tabular}

Fonte: GARCIA, 2018.

Segundo dados obtidos com os proprietários das quatro fábricas de blocos de concreto em Sinop, por semana acumulam-se em média $3.000 \mathrm{~kg}$ de resíduos de blocos por fábrica, ou seja, $48.000 \mathrm{~kg}$ por mês quantificando todas elas. Para o município de Sinop-MT, utilizando esse resíduo para compor $40 \%$ do total de agregados na fabricação de CBUQ, chega-se a aproximadamente $120.000 \mathrm{~kg}$ de material, que podem ser utilizados para pavimentar uma área de 1.875,00 metros quadrados $\left(\mathrm{m}^{2}\right)$. 
Empregar resíduos de blocos de concreto reciclados como agregados para misturas de CBUQ em obras de pavimentação é um método válido de reaproveitamento por representar elevado consumo de resíduo em um curto prazo de tempo. Esse tipo de conclusão corrobora os estudos de Arabani, Tahami e Taghipoor (2016) em que pela maior conscientização de questões ambientais e restrição dos recursos naturais, os estudos de materiais provenientes de resíduos são vantajosos em construção de pavimentos e rodovias.

Desse modo, conclui-se que a adição de resíduo de blocos de concreto na mistura asfáltica traz três benefícios imediatos: benefício tecnológico, por empregar $40 \%$ de resíduo na composição e enquadrála nos parâmetros estabelecidos pelas normas; benefício ambiental, pelo consumo do resíduo gerado pelas fábricas de blocos; benefício econômico com relação ao material betuminoso, pelo baixo teor de CAP na mistura asfáltica $(5,15 \%)$ quando confrontado com a composição analítica publicada pelo Sinapi (CAIXA, 2017) e com a pesquisa desenvolvida por Souza, Sousa e Kato (2015) em que para $25 \%$ de resíduos provenientes de mineração foi necessário 6,98\% de CAP na mistura.

\section{CONSIDERAÇÕES FINAIS}

A substituição do agregado mineral natural por agregado reciclado de resíduo de blocos de concreto no pavimento asfáltico do tipo CBUQ - faixa $C$ é viável tecnicamente. Com um agregado reciclado composto essencialmente por partículas que se encaixam na classificação miúda, pode-se substituir $40 \%$ dos agregados de origem natural em uma mistura de CBUQ faixa $C$ sem prejuízos para os aspectos físicos de estabilidade e fluência estabelecidos pelo Dnit e normativas do DNER.

A pesquisa aponta que a utilização de resíduos de matrizes cimentícias como agregado na pavimentação tem resultado satisfatório de acordo com a metodologia Marshall. No entanto, alguns critérios precisam ser avaliados para identificar a viabilidade econômica e cultural dessa utilização, ou seja, em trabalhos futuros, calcular o custo do agregado reciclado e compará-lo ao custo do agregado de origem mineral (englobando o custo de uma usina de reciclagem e manutenção) e desenvolver questionários que identifiquem a reação dos profissionais com relação à cultura do reaproveitamento de RCC.

\section{REFERÊNCIAS}

ABDOU, M. R.; BERNUCCI, L. L. B. Pavimento ecológico: uma opção para a pavimentação de vias das grandes cidades. Revista Sinal de Trânsito. 2007. Disponível em: <http: www.sinaldetransito.com.br/artigos/pavimento_ ecologico.pdf>. Acesso em: 01 abr. 2018.

AGÊNCIA NACIONAL DO PETRÓLEO. Resolução № 19, de 11.07.2005 - REGULAMENTO TÉCNICO № 3/2005.

2005. Disponível em: <http://www.abeda.org.br/wp-ontent/uploads/2017/03/RESOLU\%C3\%87\%C3\%83OANP-N\%C2\%BA-19-DE-11.7.2005-DOU-12.7.2005-REPUBLICADA-DOU-13.7.2005-RETIFICADA-DOU-25.7.2005RETIFICADA-DOU-17.3.2006.pdf>. Acesso em: 30 mai. 2017.

ARABANI, M.; TAHAMI, S. A.; TAGHIPOOR, M. Laboratory investigation of hot-mix asphalt containing waste materials. Roads Materials and Pavement Design, v. 18, n. 3, p. 713-729, mai. 2016.

ASSOCIAÇÃO BRASILEIRA DAS EMPRESAS DISTRIBUIDORAS DE ASFALTOS. Manual Básico de Emulsões Asfálticas. Rio de Janeiro, 2001. 2. ed. 2010.

ASSOCIAÇÃO BRASILEIRA DE NORMAS TÉCNICAS. NBR 7211. Agregados para concreto - Especificação. 11p. Rio de Janeiro, 2005.

BAPTISTA, J.; VIEIRA, J.; ROMANEL, C. Sustentabilidade na indústria da construção: uma logística para reciclagem dos resíduos de pequenas obras. Revista Brasileira de Gestão Urbana, Curitiba, v. 5, n. 2, p. 27-37, dez. 2013.

BERNUCCI, L. B. et al. Pavimentação Asfáltica - Formação Básica para Engenheiros. 2010. 504p. Rio de Janeiro: Petrobras e Associação Brasileira das Empresas Distribuidoras de Asfalto (Abeda), 2010. 
BONET, I. I. Valorização do resíduo areia de fundição (RAF), incorporação nas massas asfálticas do tipo CBUQ. 2002. 142f. Dissertação (Mestrado) - Departamento de Engenharia de Produção da Universidade Federal de Santa Catarina, Florianópolis.

BRASILEIRO, L. L. et al. Analysis of the Properties of Asphaltic Concrete Using Recycled Aggregates of CDW. Materials Science Forum, v. 775-776, p. 613-618, 2014.

CAIXA ECONÔMICA FEDERAL. Catálogo de Composições Analíticas. Nov. 2017. Disponível em: <http://www. caixa.gov.br/site/Paginas/downloads.aspx\#categoria_650>. Acesso em: 10 jan. 2018.

COBBOLD, P. R. et al. Radial patterns of bitumen dykes around Quaternary volcanoes, provinces of northern Neuquén and southernmost Mendoza, Argentina. Journal of South American Earth Sciences. Mendoza, Argentina, v. 56, p. 454-467. 2014.

CONSELHO NACIONAL DO MEIO AMBIENTE. Resolução $\mathrm{n}$ 307, de 05 de julho de 2002: Estabelece diretrizes, critérios e procedimentos para a gestão dos resíduos da Construção Civil. Diário Oficial da União, 17 jul. 2002. Brasília, DF.

DEPARTAMENTO NACIONAL DE ESTRADAS DE RODAGEM. DNER-ME 093. Determinação de Densidade Real Método de Ensaio. Rio de Janeiro, 1994.

DEPARTAMENTO NACIONAL DE ESTRADAS DE RODAGEM. DNER-ME 043. Misturas betuminosas a quente Ensaio Marshall - Método de Ensaio. Rio de Janeiro, 1995.

DEPARTAMENTO NACIONAL DE ESTRADAS DE RODAGEM. DNER-ME 054. Equivalente de Areia - Método de Ensaio. Rio de Janeiro, 1997.

DEPARTAMENTO NACIONAL DE ESTRADAS DE RODAGEM. DNER-ME 195. Determinação da Absorção e Massa Específica de Agregado Graúdo - Método de Ensaio. Rio de Janeiro, 1997.

DEPARTAMENTO NACIONAL DE ESTRADAS DE RODAGEM. EM 367. Material de enchimento para misturas betuminosas: Especificação de Material. Rio de Janeiro, 1997.

DEPARTAMENTO NACIONAL DE ESTRADAS DE RODAGEM. ME 035. Agregados: determinação da abrasão “Los Angeles". Rio de Janeiro, 1998.

DEPARTAMENTO NACIONAL DE ESTRADAS DE RODAGEM. DNER-ME 083. Agregados: análise granulométrica Método de Ensaio. Rio de Janeiro, 1998.

DEPARTAMENTO NACIONAL DE INFRAESTRUTURA DE TRANSPORTES. DNIT-ES 031. Pavimentos Flexíveis Concreto Asfáltico - Especificação de Serviço. Rio de Janeiro, 2006.

DIAS, T. W.; JÚNIOR, L. R. Análise da viabilidade de implantação de um sistema de gerenciamento de resíduos da construção civil na obra da escola Pro-infância creche Damasco no município de Varginha - MG. REEC - Revista Eletrônica de Engenharia Civil, v. 11, n. 2, mar. 2016.

GARCIA, G. M. Uso de resíduos de concreto na fabricação de pavimento asfáltico. 2018. 78f. Dissertação (Mestrado) - Programa de Pós-Graduação em Ciências Ambientais. Universidade Federal de Mato Grosso, Sinop.

INSTITUTO DE PESQUISA ECONÔMICA APLICADA. Diagnóstico dos Resíduos Sólidos da Construção Civil Relatório de Pesquisa. Brasília, 2012. Disponível em: <http://www.ipea.gov.br/agencia/images/stories/PDFs/ relatoriopesquisa/120911_relatorio_construcao_civil.pdf>. Acesso em: 30 mai. 2017.

LIMA, A. S.; CABRAL, A. E. B. Caracterização e classificação dos resíduos de construção civil da cidade de Fortaleza (CE). Engenharia Sanitária e Ambiental, Cratéus, v. 18, n. 2, p. 169-176, abr./jun. 2013.

MATO GROSSO. Secretaria de Estado da Infraestrutura e Logística. Pregão Eletrônico n. 002/2017 (Superintendência de Aquisições e Licitações - Sual). Cuiabá, 2017. Disponível em: <http://www.sinfra.mt.gov.br/-/6428019-pregaoeletronico-n.-002/2017-superintendencia-de-aquisicoes-e-licitacoes-sual->. Acesso em: 15 mar. 2018. 
PAIVA, T. S.; CARTAXO, E. F. Misturas asfálticas quentes: impactos ambientais e utilização do RCD. Revista T\&C Amazônia, nov. 2014. Disponível em: <http://www.fucapi.br/tec/2014/01/31/misturas-asfalticas-quentesimpactos-ambientais-e-utilizacao-do-rcd/>. Acesso em: 13 dez. 2017.

PASSADÍN, A. R.; PÉREZ, I. Laboratory evaluation of hot-mix asphalt containing construction and demolition waste. Construction and Building Materials, v. 43, p. 497-505, jun. 2013.

PEREIRA, R. S. Responsabilidade social empresarial e empresa sustentável: da teoria à prática. Revista de Administração Contemporânea, v. 14, n. 6, p.1174-1176, dez. 2010.

PERSICH, J. C.; SILVEIRA, D. D. Gerenciamento de Resíduos Sólidos - A importância da educação ambiental no processo de implantação da coleta seletiva de lixo - O caso de ljuí/RS. Revista Eletrônica em Gestão, Educação e Tecnologia Ambiental, Santa Maria, v. 4, n. 4, p. 416-426, 2011.

PESTANA, R. Contribuição para o Estudo do Comportamento Mecânico de Resíduos de Construção e Demolição Aplicados em Estradas de Baixo Tráfego. 2008. 193f. Dissertação (Mestrado) - Departamento de Engenharia Civil do IST da Universidade Técnica de Lisboa, Lisboa.

PINTO, S. Materiais Pétreos e Concreto Asfáltico: conceituação e dosagem. Rio de Janeiro: Instituto Militar de Engenharia, 2006.

REYES-ORTIZ, O. J.; ALVAREZ, A.; VALDES-VIDAL, G. A. Evaluation mecánica de mezclas asfálticas frías fabricadas con reemplazo de llenante mineral. Información Tecnológica. v. 25, n. 2, p. 93-102, out. 2014.

RODRIGUES, C. R. S.; FUCALE, S. Dosagem de concretos produzidos com agregado miúdo reciclado de resíduo da construção civil. Ambiente Construído, v. 14, p. 99-111, jan./mar. 2014.

SANTOS, M. R.; DEMUELENAERE, R. G. A. Reciclagem de Pavimento Asfáltico a Quente In Situ. Revista Científica Multidisciplinar Núcleo do Conhecimento. v. 01, p. 5-16, jan. 2018.

SILVA, V. A. D.; FERNANDES, A. L. T. Cenário do gerenciamento dos resíduos da construção e demolição (RCD) em Uberaba-MG. Sociedade \& Natureza, Uberlândia, v. 24, n. 2, p. 333-344, ago. 2012.

SOUZA, J. A.; SOUSA, J. M.; KATO, R. B. Análise do desempenho de concreto betuminoso usinado a quente com adição de rejeito da mineração do cobre segundo os parâmetros Marshall. Engineering and Science, v. 2, n. 4, p. 3-12, out. 2015.

SOUZA, L. M. de; ASSIS, C. D. de; SOUTO, S. B. G. Agregado reciclado: um novo material de construção civil. Revista Eletrônica em Gestão, Educação e Tecnologia Ambiental - Reget. Santa Maria: Centro de Ciências Naturais e Exatas - UFSM, v. 18, n. 1, p. 273-278, abr. 2014.

WESSELING, D. H. Estudo do comportamento mecânico de misturas em concreto asfáltico com incorporação de resíduos industriais. 2005. 144f. Dissertação (Mestrado) - Departamento de Engenharia Civil da Universidade Federal do Rio Grande do Sul, Porto Alegre. 